\title{
Thermal magnetic resonance: physics considerations and electromagnetic field simulations up to 23.5 Tesla $(1 \mathrm{GHz})$
}

Lukas Winter ${ }^{1 *}$, Celal Oezerdem ${ }^{1}$, Werner Hoffmann ${ }^{2}$, Tessa van de Lindt ${ }^{1}$, Joao Periquito ${ }^{1}$, Yiyi $_{\mathrm{Ji}}{ }^{1}$, Pirus Ghadjar ${ }^{3}$, Volker Budach ${ }^{3}$, Peter Wust ${ }^{3}$ and Thoralf Niendorf ${ }^{1,4,5}$

\begin{abstract}
Background: Glioblastoma multiforme is the most common and most aggressive malign brain tumor. The 5-year survival rate after tumor resection and adjuvant chemoradiation is only $10 \%$, with almost all recurrences occurring in the initially treated site. Attempts to improve local control using a higher radiation dose were not successful so that alternative additive treatments are urgently needed. Given the strong rationale for hyperthermia as part of a multimodal treatment for patients with glioblastoma, non-invasive radio frequency (RF) hyperthermia might significantly improve treatment results.
\end{abstract}

Methods: A non-invasive applicator was constructed utilizing the magnetic resonance (MR) spin excitation frequency for controlled RF hyperthermia and MR imaging in an integrated system, which we refer to as thermal MR. Applicator designs at RF frequencies $300 \mathrm{MHz}, 500 \mathrm{MHz}$ and $1 \mathrm{GHz}$ were investigated and examined for absolute applicable thermal dose and temperature hotspot size. Electromagnetic field (EMF) and temperature simulations were performed in human voxel models. RF heating experiments were conducted at $300 \mathrm{MHz}$ and $500 \mathrm{MHz}$ to characterize the applicator performance and validate the simulations.

Results: The feasibility of thermal MR was demonstrated at 7.0 T. The temperature could be increased by $\sim 11^{\circ} \mathrm{C}$ in 3 min in the center of a head sized phantom. Modification of the RF phases allowed steering of a temperature hotspot to a deliberately selected location. RF heating was monitored using the integrated system for MR thermometry and high spatial resolution MRI. EMF and thermal simulations demonstrated that local RF hyperthermia using the integrated system is feasible to reach a maximum temperature in the center of the human brain of $46.8^{\circ} \mathrm{C}$ after 3 min of RF heating while surface temperatures stayed below $41^{\circ} \mathrm{C}$. Using higher RF frequencies reduces the size of the temperature hotspot significantly.

Conclusion: The opportunities and capabilities of thermal magnetic resonance for RF hyperthermia interventions of intracranial lesions are intriguing. Employing such systems as an alternative additive treatment for glioblastoma multiforme might be able to improve local control by "fighting fire with fire". Interventions are not limited to the human brain and might include temperature driven targeted drug and MR contrast agent delivery and help to understand temperature dependent bio- and physiological processes in-vivo.

Keywords: Thermal magnetic resonance, Magnetic resonance imaging, Hyperthermia, Radio frequency, RF coil technology, Gliablastoma multiforme, Radiation oncology, Thermometry, Targeted drug delivery, Thermal therapies

\footnotetext{
* Correspondence: Lukas.Winter@mdc-berlin.de

${ }^{1}$ Berlin Ultrahigh Field Facility (B.U.F.F.), Max-Delbrück Center for Molecular Medicine, Berlin, Germany

Full list of author information is available at the end of the article
}

\section{() Biomed Central}

(c) 2015 Winter et al. Open Access This article is distributed under the terms of the Creative Commons Attribution 4.0 International License (http://creativecommons.org/licenses/by/4.0/), which permits unrestricted use, distribution, and reproduction in any medium, provided you give appropriate credit to the original author(s) and the source, provide a link to the Creative Commons license, and indicate if changes were made. The Creative Commons Public Domain Dedication waiver (http://creativecommons.org/publicdomain/zero/1.0/) applies to the data made available in this article, unless otherwise stated. 


\section{Background}

Glioblastoma multiforme is the most common and most aggressive malign brain tumor. Despite demarcation in computed tomography (CT) or magnetic resonance imaging (MRI) glioblastoma multiforme presents no clear microscopic barriers towards the unaffected brain [1]. This pathology makes a complete surgical resection challenging if not elusive. Recurrences are typically located in the former tumor region and therefore intensification of local treatment is required. Yet, the first therapeutic attempt is to resect the tumor as completely as possible. Radiation therapy adjuvant to resection improves overall survival versus resection alone [2]. Since 2004 the standard of care consists of combined adjuvant chemoradiation using temozolomide [3]. Arguably, the 5-year survival rate after tumor resection and adjuvant chemoradiation is only $10 \%$, with almost all recurrences occurring in the initially treated site [3, 4]. Attempts to improve local control using a higher radiation dose were not successful [5] so that alternative additive treatments are urgently needed. Interstitial hyperthermia in addition to external beam radiation therapy and brachytherapy of the brain has been demonstrated to improve survival in a randomized trial [6]. This type of treatment is not applicable to all tumor locations within the brain, and did not become accepted in clinical practice due to its invasive nature.

Another thermal therapy approach is nanotherapy, where a dispersion of iron-oxide (magnetite) nanoparticles is injected into the tumor which is subsequently heated in an alternating magnetic field [7]. This therapy was evaluated in combination with a reduced dose of external beam radiation (median dose $30 \mathrm{~Gy}$ ) in a singlearm study with patients predominantly with recurrent glioblastoma [8]. The treatment was well received and appeared effective. Notwithstanding this clinical success nanotherapy assumes a sufficient coverage of the tumor region by the nanoparticles, which can be difficult under clinical conditions. In addition, the efficiency of the currently available nanoparticles and the frequency of the magnetic field constitute constraints which require further technological improvements. In this light, nanotherapy for glioblastoma is presently considered not to be ready for routine clinical use. Given the strong rationale for the successful use of hyperthermia as part of a multimodal treatment for patients with glioblastoma [9], noninvasive radiofrequency (RF) hyperthermia might significantly improve treatment results, in addition to standard chemoradiation. To evaluate treatment efficiency noninvasive three dimensional thermal dose evaluation is necessary [10]. MRI is of proven diagnostic value with an ever growing number of applications that support thermal therapies $[11,12]$. In current clinical regional RF hyperthermia practice MR thermometry (MRTh) is used for spatiotemporal monitoring of temperature and treatment efficiency [13-15]. While the RF transmission used for MRI is commonly performed at a frequency of $64 \mathrm{MHz}\left(B_{0}=1.5 \mathrm{~T}\right)$, RF transmission induced heating interventions in this hybrid systems are achieved with $\mathrm{RF}$ antennas usually driven at $\sim 100 \mathrm{MHz}$ [16]. The RF wavelength at $100 \mathrm{MHz}$ is approximately $33 \mathrm{~cm}$ in brain tissue, which is not suitable to focus the electromagnetic (EM) energy selectively enough to brain tumors with a tumor size of few centimeters. Higher RF frequencies ( $>100 \mathrm{MHz}$ ) are suitable to be applied in the head and neck region to perform localized RF hyperthermia [17-20]. Unfortunately, established systems still lack the ability of non-invasive 3D temperature measurement to monitor and control the thermal dose applied in the treated region and in healthy tissue. Realizing this challenge it was demonstrated, that ultrahigh magnetic fields (UHF, $B_{0} \geq 7.0 \mathrm{~T}$ ) render an integrated applicator feasible; including a configuration suitable for MRI, MRTh and controlled targeted RF heating utilizing a single transmission frequency of $300 \mathrm{MHz}$ [20]. The applicator employs the proton MR frequency for targeted RF heating and can be used together with commercially available MR systems and multi-channel RF transmission configurations for imaging diagnostics and for RF hyperthermia applications [20]. Such integrated system will be referred to as thermal MR. The early results indicated that this approach is conceptually appealing for a therapeutic application to intracranial lesions since pretreatment diagnosis and planning, peri-treatment thermal dose control and adaptation and post-treatment evaluation of the treatment efficiency can be performed with a single device. Recognizing this opportunity this work presents physics considerations together with preclinical results derived from a thermal MR applicator driven at $300 \mathrm{MHz}$. For comparison, applicator designs are proposed which are capable of utilizing even higher RF frequencies (up to $1 \mathrm{GHz}$ ). This approach holds the promise to benefit an effective reduction of the achievable thermal hotspot size. To meet this goal electromagnetic field (EMF) simulations are performed in a human voxel model deduced from a healthy volunteer. Physics considerations and RF antenna designs are presented for $300 \mathrm{MHz}, 500 \mathrm{MHz}$ and $1 \mathrm{GHz}$ which correspond to $7.0 \mathrm{~T}, 11.7 \mathrm{~T}$ or $23.5 \mathrm{~T}$ with an effective wavelength of approximately $13.5 \mathrm{~cm}, 8.6 \mathrm{~cm}$ and $4.5 \mathrm{~cm}$ in brain tissue. These efforts are complemented by $\mathrm{RF}$ heating experiments conducted at $500 \mathrm{MHz}$. The preliminary results suggest that such high frequency systems could be used in two configurations. (i) an integrated thermal MR application [20] in conjunction with a $7.0 \mathrm{~T}$, $11.7 \mathrm{~T}$ or $23.5 \mathrm{~T}$ UHF MR system or (ii) a hybrid configuration $[21,22]$ using an external RF power amplifier for RF heating together with a conventional MR systems at $1.5 \mathrm{~T}$ or $3.0 \mathrm{~T}$. The merits and limitations of physics, technology and clinical applicability of thermal MR are discussed in 
the context of adjuvant RF hyperthermia treatment of intracranial lesions.

\section{Methods}

\section{Ethics statement}

All imaging studies were performed after due approval by the local ethical committee (registration number DE/ CA73/5550/09, Landesamt für Arbeitsschutz, Gesundheitsschutz und technische Sicherheit, Berlin, Germany). Informed written consent was obtained from each volunteer prior to the study. For the in-vivo proof-ofconcept study at $7.0 \mathrm{~T}, 1$ healthy subject without any known history of neuro- or cardiovascular diseases was included.

\section{Thermal MR applicator and RF antenna design}

A thermal MR applicator was constructed to be operated with a $300 \mathrm{MHz}\left(B_{0}=7.0 \mathrm{~T}\right) \mathrm{MR}$ scanner (Siemens Healthcare, Erlangen, Germany). The applicator consists of eight antenna building blocks placed in a symmetrical arrangement around a cylindrical phantom (Fig. 1a). The building blocks are driven by an 8-channel multitransmit system of the MR scanner (TX-Array, Siemens Healthcare, Erlangen, Germany) utilizing an $8 \times 1 \mathrm{~kW}$ array of pulsed RF power amplifiers (Stolberg HF Technik AG, Stolberg-Vicht, Germany) (Fig. 1b) [20]. The pulsed power amplifier allows to be driven at $\mathrm{P}_{\max }$ with $10 \%$ duty cycle and a pulse length of $5 \mathrm{~ms}$ resulting in an average power of $800 \mathrm{~W}$. For a short period the duty cycle can be increased to $>20 \%$ doubling the available average power. Each antenna building block consists of a $\lambda / 2$ electric dipole antenna in a bow tie shape and a high permittivity dielectric (Deuteriumoxide $\left(\mathrm{D}_{2} \mathrm{O}\right)$, isotopic purity 99.9 atom $\% \mathrm{D}, \varepsilon_{r}=80$ ) [20]. The use of $\mathrm{D}_{2} \mathrm{O}$ as a substrate facilitates ${ }^{1} \mathrm{H}$ MRI free of signal contributions from deuterium since the gyromagnetic ratio of ${ }^{2} \mathrm{H}$ deviates from hydrogen. This prevents artefacts due to limitations in the dynamic imaging range caused by strong $B_{1}^{+}$field contributions in the vicinity of the electric dipole antenna. The high permittivity of the substrate allows shortening of the electric dipole length of the antenna since the wavelength in this medium is reduced by approximately $\sqrt{ } \varepsilon_{r}$. This

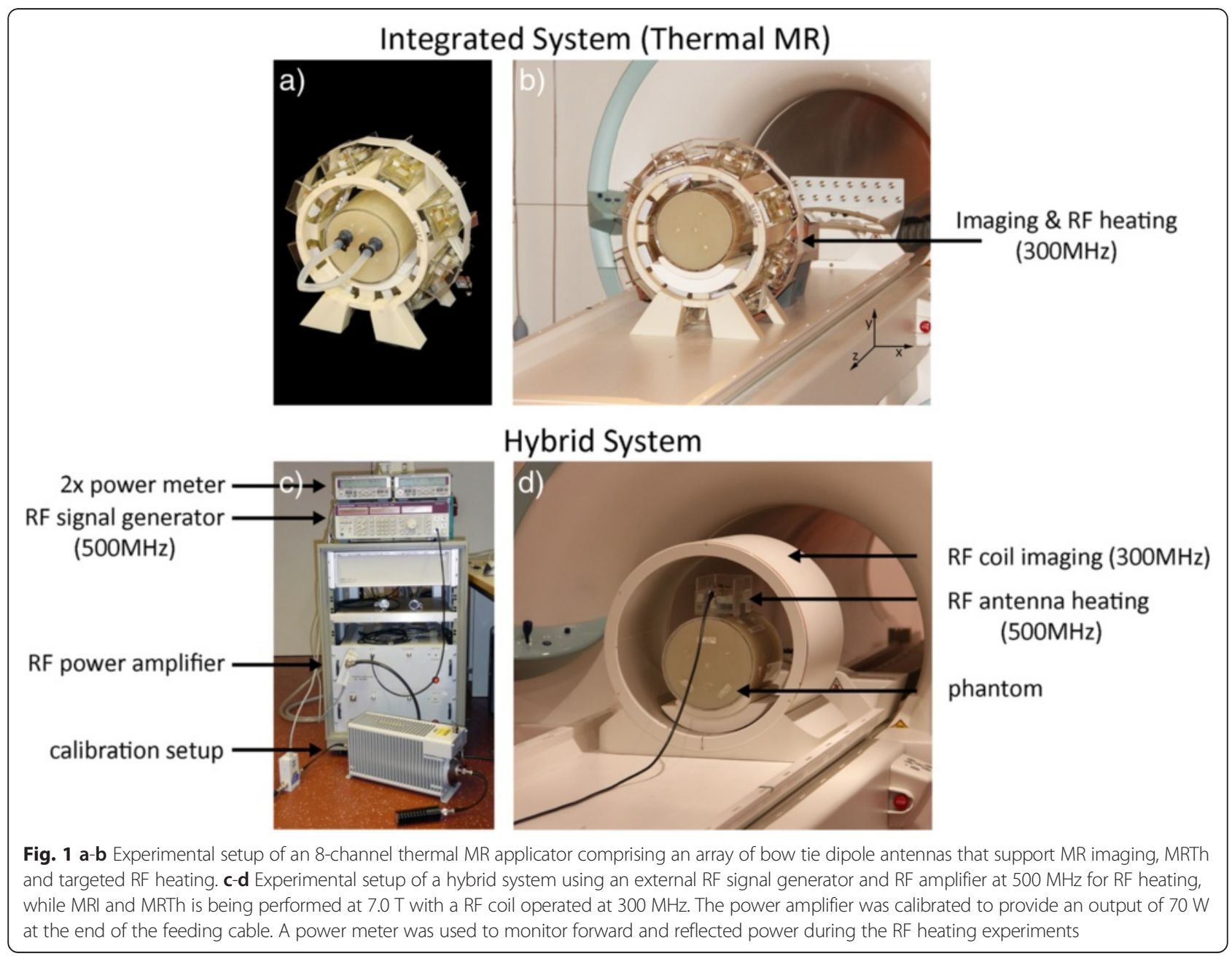


enables antenna positioning around the human head with an application in the human brain. The Poynting vector of such arrangement is directed towards the target region for RF heating and MRI, with the $E$-fields being parallel to the electric dipole which are aligned with the direction of the static magnetic field $B_{O}$ (z-direction). In the radio frequency range induced temperature elevations are predominantly caused by E-fields [23], which are the dominant factor of power absorption in tissue as expressed by the specific absorption rate (SAR):

$$
S A R=\frac{\sigma(f)|\vec{E}|^{2}}{\rho}
$$

with $\sigma(f)$ the frequency dependent electrical conductivity of tissue, $\rho$ the tissue density and $|\vec{E}|^{2}$ the amplitude of the electric field vector. The $H$-fields perpendicular to $B_{O}$ (x-y-direction) form the spin excitation field $B_{1}^{+}$to be exploited for MRI and MRTh.

Even though certain ceramics (e.g., $\mathrm{BaTiO}_{3}$ ) can be used as a substrate with lower loss tangents than $\mathrm{D}_{2} \mathrm{O}$, a liquid dielectric is preferred as a substrate in our implementation. An RF hyperthermia application with high RF power might lead to temperature elevations in the substrate caused by RF losses or thermal conductivity. The temperature dependence of the electromagnetic properties and hence the impedance of the substrate exhibits the risk to increase power reflections due to impedance mismatch during the cause of a treatment. A liquid dielectric offers the flexibility and benefit to be used in a temperature control circuit to stabilize the substrate temperature.

\section{Electromagnetic field simulations}

To investigate the EMF and SAR distribution, finite integration technique simulations were performed with CST Microwave Studio 2012 (CST, Darmstadt, Germany). Employing higher RF frequencies $(f>300 \mathrm{MHz})$ allows to reduce the size of the power absorption hotspot along $\mathrm{x}$-, $y$ - and z-dimension. In the $x$-y-plane (Fig. 1b) the hotspot size is determined by the RF wavelength in a lossy dielectric or brain tissue. The hotspot dimensions along the $\mathrm{z}$-direction can be reduced by decreasing the size of the dielectric at higher RF frequencies, which allows for smaller transmit elements along that axis or by the use of multiple antenna rings [24-26]. To quantify these effects, SAR distributions produced by two 8-channel setups consisting of RF antenna building blocks with a fixed substrate size of $(150 \times 70 \times 40) \mathrm{mm}^{3}$ were examined at $300 \mathrm{MHz}$ and $500 \mathrm{MHz}$ (Fig. 2a, b, d, e). These configurations were benchmarked against a smaller substrate size of $(70 \times 40 \times 20) \mathrm{mm}^{3}$ at $500 \mathrm{MHz}($ Fig. $2 \mathrm{c}, \mathrm{f})$. For this purpose the antennas were placed around a cylindrical phantom (diameter $=180 \mathrm{~mm}$, length $=250 \mathrm{~mm}$ ) with tissue properties $\left(\varepsilon_{r}=75, \sigma=0.72 \mathrm{~S} / \mathrm{m}\right)$. The effective dimensions of deep lying hotspots were analysed using iso-contour calculations of the SAR distribution. For this purpose isoSAR $25 \%$, iso-SAR $50 \%$, iso-SAR $75 \%$ and an iso-SAR $90 \%$ thresholds were derived for $x-, y-$ and $z-$ dimension based on the maximum point SAR value. SAR1g (1 g average, IEC 62407-1) was calculated for human voxel "Ella" from the virtual family [27].

\section{Hybrid RF heating at $500 \mathrm{MHz}$}

To validate the results derived from the numerical simulations and to demonstrate that the RF frequency used

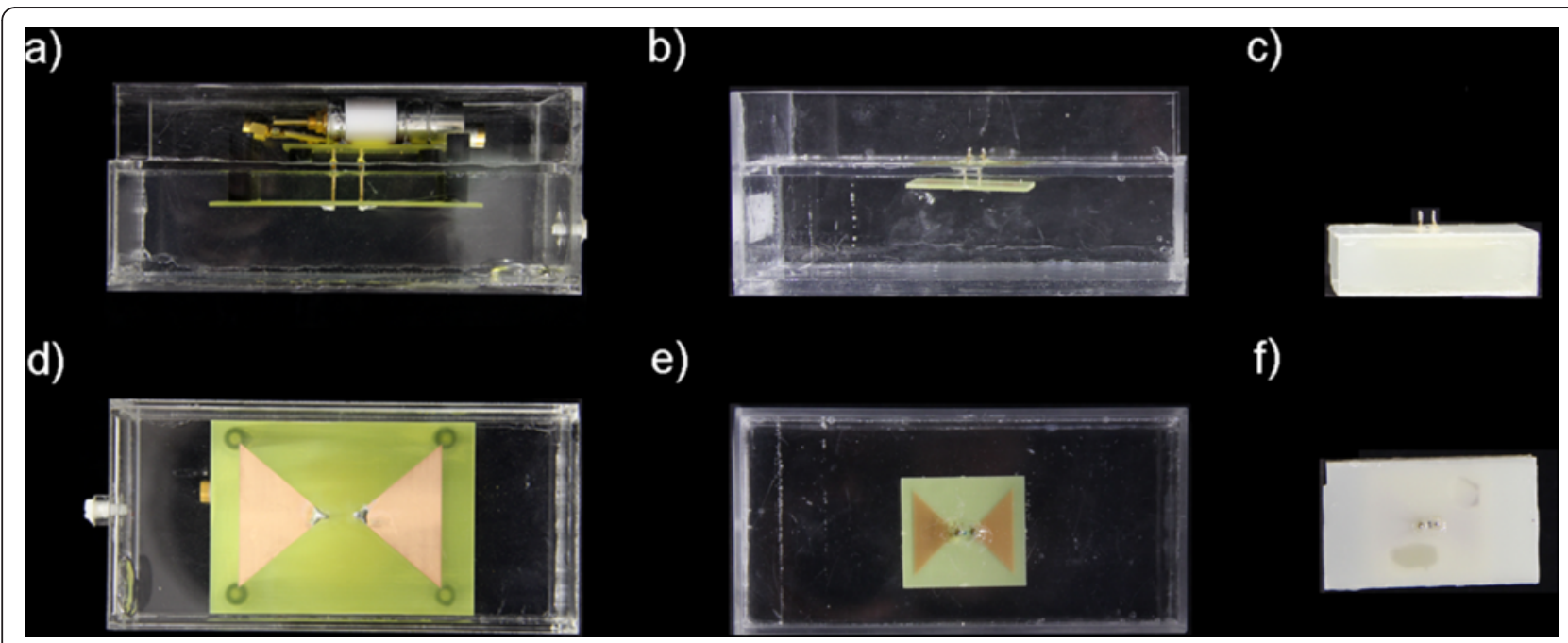

Fig. 2 a-f Constructed bow tie building blocks used for RF heating in an integrated or hybrid system (a-c) sagittal and (d-f) coronal view. (a,d) $300 \mathrm{MHz}$ setup with the dimensions $(150 \times 70 \times 40) \mathrm{mm}^{3}$ and $\mathrm{D}_{2} 0$ as a substrate. $(\mathbf{b}, \mathbf{e}) 500 \mathrm{MHz}$ setup with the dimensions $(150 \times 70 \times 40) \mathrm{mm} \mathrm{m}^{3}$ and $(c, f)$ with the dimensions $(70 \times 40 \times 20) \mathrm{mm}^{3}$, while deionized water has been used as a substrate 
for targeted RF heating may differ from the magnetic resonance frequency used for MRTh, RF heating experiments were performed at $500 \mathrm{MHz}$ while MRI and MRTh was conducted at 7.0 T (300 MHz). The RF heating setup of the hybrid approach is shown in Fig. 1b and consists of a signal generator (Rhode \& Schwarz, Munich, Germany), a class A linear RF power amplifier (RFPA) module (LZY-1, Mini-Circuits, New York, USA) capable to provide a continuous wave output power of $\sim \mathrm{P}_{\text {out }}=$ $140 \mathrm{~W}$ at $\mathrm{f}=100-500 \mathrm{MHz}$ and two power reflection meters (Rhode \& Schwarz, Munich, Germany). One power meter was used to monitor transmitted and reflected power during the experiments, while the other power meter was used together with a $30 \mathrm{~dB}$ damping and a $50 \Omega$ termination to calibrate the RF losses introduced by the RF cable connecting the RFPA and the antenna. A single bow tie dipole antenna $(150 \times 70 \times 40) \mathrm{mm}^{3}$ was applied to induce RF heating in a custom made cylindrical phantom $($ diameter $=180 \mathrm{~mm}$, length $=250 \mathrm{~mm})($ Fig. $2 \mathrm{~b}, \mathrm{e})$. The phantom has an outer shell of polymethylmethacrylate filled with a mixture of deionized water, copper sulfate $\left(\mathrm{Cu}(\mathrm{II})-\mathrm{SO}_{4}, 0.74 \mathrm{~g} / \mathrm{l}\right)$ and sodium chloride $(\mathrm{NaCl}, 3.33 \mathrm{~g} / \mathrm{l})$ to resemble conductivity and permittivity of brain tissue. Agarose $\left(\mathrm{C}_{12} \mathrm{H}_{18} \mathrm{O}_{9}, 20 \mathrm{~g} / \mathrm{l}\right)$ was used as a gelling agent to suppress thermal convection. The resulting electromagnetic properties $\left(\varepsilon_{r}=72, \sigma=0.75 \mathrm{~S} / \mathrm{m}\right)$ were measured based on impedance measurements with a network analyzer (Agilent 4296B, Santa Clara, CA, USA). For RF heating an input power of $70 \mathrm{~W}$ was calibrated at the antennas feeding point. An RF heating duration of $12 \mathrm{~min}$ was used. To support ${ }^{1} \mathrm{H}$ MRTh, the setup was placed inside a birdcage volume RF coil (Siemens Healthcare, Erlangen, Germany, $f=300 \mathrm{MHz}$, inner diameter $=34 \mathrm{~cm}$ ). As a high permittivity substrate for the RF heating antennas at $500 \mathrm{MHz}$ deionized water was used instead of $\mathrm{D}_{2} 0$. In this particular arrangement the $B_{1}^{+}$amplitude in the substrate and the phantom exhibits signal variations that fall well within the dynamic imaging range while the electromagnetic properties (RF losses and permittivity) of both $\mathrm{D}_{2} \mathrm{O}$ and $\mathrm{H}_{2} \mathrm{O}$ are comparable. MRTh was conducted using the proton resonance frequency shift (PRFS) method with a dual gradient echo technique $\left(\mathrm{TE}_{1}=\right.$ $22.6 \mathrm{~ms}, \mathrm{TE}_{2}=6.34 \mathrm{~ms}$ ) and a spatial resolution of
$(1.9 \times 1.9 \times 5) \mathrm{mm}^{3}[28,29] . B_{0} \operatorname{drift}(0.02 \mathrm{ppm} / \mathrm{h})$ was compensated with a vegetable oil sample as a reference [30].

\section{Thermal simulations}

For a more realistic scenario, EMF simulations were performed with the voxel model "Ella" from the virtual family [27] at $300 \mathrm{MHz}, 500 \mathrm{MHz}$ and $1 \mathrm{GHz}$. All electromagnetic properties of the voxel model are based on [31]. The values for brain grey and white matter and blood are surveyed in Table 1. To demonstrate an advantage of even higher RF frequencies for a more localized RF heating, a 20-channel antenna array consisting of electrical dipole antennas (length $=142 \mathrm{~mm}$ ) driven at $1 \mathrm{GHz}$ was implemented and compared with the $300 \mathrm{MHz}$ and $500 \mathrm{MHz}$ setups. SAR distributions were calculated for an in-phase $\left(0^{\circ}\right.$ phase shift between channels) phase setting. The power loss distribution was used as an input for the thermal simulations. Thermal simulations were conducted using CST MPhysics (CST, Darmstadt, Germany) solving the bioheat transfer equation:

$$
\begin{aligned}
c_{t} \rho_{t} \frac{\partial T}{\partial t}= & \nabla k \nabla T+\rho_{t}(S A R) \\
& +A-\rho_{b} c_{b} \rho_{t} F_{t}\left(T-T_{b}\right)
\end{aligned}
$$

with the specific heat of tissue $c_{t}$ in $\left[J /\left(\mathrm{kg} \cdot{ }^{\circ} \mathrm{C}\right)\right]$, the tissue density $\rho_{t}$ in $\left[\mathrm{kg} / \mathrm{m}^{3}\right]$, tissue temperature $T$ in $\left[{ }^{\circ} \mathrm{C}\right]$, thermal conductivity of tissue $k$ in $\left[W /\left(m \cdot{ }^{\circ} \mathrm{C}\right)\right]$, the basal metabolic heat generation rate of tissue $A$ in $[W / k g]$, the blood density $\rho_{b}=1060 \mathrm{~kg} / \mathrm{m}^{3}$, the specific heat of blood $c_{b}=3900 \mathrm{~J} /\left(\mathrm{kg} \cdot{ }^{\circ} \mathrm{C}\right)$, the tissue heat transfer rate $F_{t}$ in $[\mathrm{ml} /(\mathrm{min} \cdot \mathrm{kg})]$ and the blood temperature $T_{b}=37^{\circ} \mathrm{C}$. The heat capacity and thermal conductivity of the phantom material was $c_{\text {phantom }}=3546 \mathrm{~J} /\left(\mathrm{kg} \cdot{ }^{\circ} \mathrm{C}\right)$ and $k_{\text {phantom }}=$ $0.53 \mathrm{~W} /\left(\mathrm{m} \cdot{ }^{\circ} \mathrm{C}\right)$ respectively. Please note that the basal metabolic heat generation rate and the term related to blood perfusion in Eq.2 are not considered for the thermal simulations in the phantom. The head of the human voxel model "Ella" from the virtual family was used, with a voxel size of $(2 \times 2 \times 2) \mathrm{mm}^{3}$ and thermally adjusted parameters based on [31]. All thermal parameters can be found in [31], thermal values for grey and white matter of the brain and blood are summarized in Table 1. RF heating in the

\begin{tabular}{|c|c|c|c|c|c|c|c|c|c|c|c|}
\hline \multirow[t]{2}{*}{ Tissue } & \multicolumn{3}{|c|}{ Permittivity } & \multicolumn{3}{|c|}{ Electrical conductivity [S/m] } & \multirow{2}{*}{$\begin{array}{l}\text { Density } \\
{\left[\mathrm{kg} / \mathrm{m}^{3}\right]}\end{array}$} & \multirow{2}{*}{$\begin{array}{l}\text { Heat } \\
\text { capacity } \\
{\left[\mathrm{J} / \mathrm{kg} /{ }^{\circ} \mathrm{C}\right]}\end{array}$} & \multirow{2}{*}{$\begin{array}{l}\text { Thermal } \\
\text { conductivity } \\
{\left[\mathrm{W} / \mathrm{m} /{ }^{\circ} \mathrm{C}\right]}\end{array}$} & \multirow{2}{*}{$\begin{array}{l}\text { Heat transfer } \\
\text { rate }[\mathrm{ml} / \mathrm{min} / \mathrm{kg}]\end{array}$} & \multirow{2}{*}{$\begin{array}{l}\text { Heat } \\
\text { generation } \\
\text { rate }[W / \mathrm{kg}]\end{array}$} \\
\hline & $300 \mathrm{MHz}$ & $500 \mathrm{MHz}$ & $1 \mathrm{GHz}$ & $300 \mathrm{MHz}$ & $500 \mathrm{MHz}$ & $1 \mathrm{GHz}$ & & & & & \\
\hline White matter & 43.8 & 41 & 38.6 & 0.41 & 0.47 & 0.62 & 1041 & 3583 & 0.48 & 212 & 4.32 \\
\hline Grey matter & 60 & 55.8 & 52.3 & 0.69 & 0.78 & 0.99 & 1045 & 3696 & 0.55 & 764 & 15.54 \\
\hline Blood & 65.7 & 63.3 & 61.1 & 1.32 & 1.38 & 1.58 & 1060 & 3900 & 0.52 & 10000 & 0 \\
\hline
\end{tabular}

Table 1 Electromagnetic and thermal properties of brain tissue

Electromagnetic and thermal properties for $300 \mathrm{MHz}, 500 \mathrm{MHz}$ and $1 \mathrm{GHz}$ of brain grey matter, brain white matter and blood used in the electromagnetic simulations with the human voxel model "Ella" [28]. All other material parameters used in the electromagnetic field simulations (e.g., skin or fat) can be found in [29] 
voxel model was simulated for a duration of 3 min with a constant input power of $400 \mathrm{~W}$ per applicator. This approach resulted in an effective input power of $50 \mathrm{~W}$ per antenna at $300 \mathrm{MHz}$ and $500 \mathrm{MHz}$ and $20 \mathrm{~W}$ per antenna at $1 \mathrm{GHz}$. RF antenna and RF component losses were not taken into account. A water bolus of a fixed temperature of $20^{\circ} \mathrm{C}$ was used to cool the surface. The effective dimensions of deep lying temperature hotspots were analysed using iso-contour calculations of the temperature difference with regards to baseline temperature $\left(37^{\circ} \mathrm{C}\right)$. For this purpose iso-Temperature $90 \%$, iso-Temperature $75 \%$, iso-Temperature $50 \%$ and iso-Temperature $25 \%$ thresholds were derived based on the maximum overall temperature increase.

\section{Results and discussion}

Thermal MR applicator and antenna design

The thermal MR 8-channel applicator supports high spatial resolution MRI at $7.0 \mathrm{~T}$ (Fig. 3a-b), MRTh (Fig. 3c-d) and targeted RF heating (Fig. 3c-d) in a cylindrical phantom mimicking brain tissue properties and the size of a human head [20]. The RF power of the MR system is sufficient to increase the temperature by approximately $11{ }^{\circ} \mathrm{C}$ in $3 \mathrm{~min}$ (Fig. 3c) [20]. The multichannel transmit system of the MR scanner can be used to deliberately alter and steer the location of the hotspot (Fig. 3d) [20]. Thermal simulations in a human voxel model demonstrated that these phase settings can be reproduced to generate a hotspot in the center (Fig. 3e)

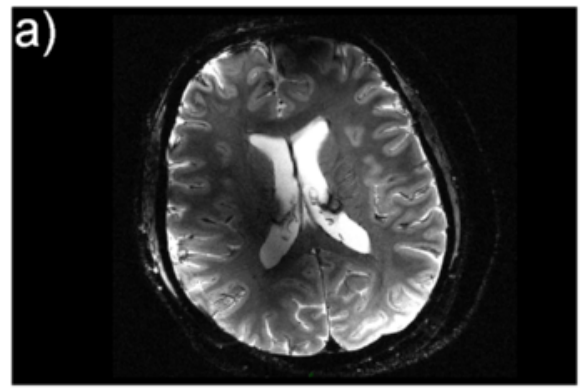

C)

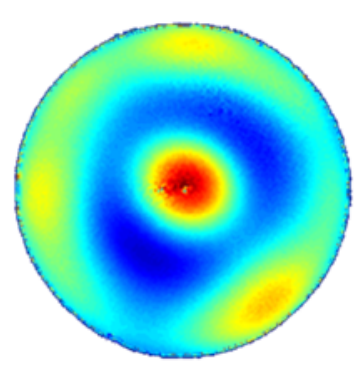

e)

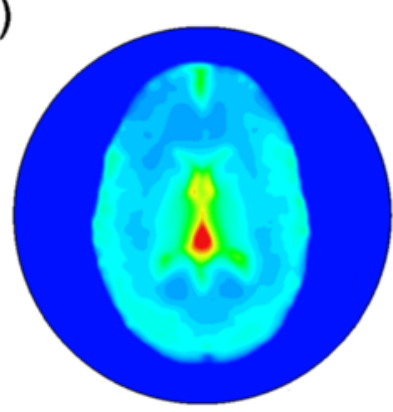

$\Delta \mathrm{T}$ in $\left[{ }^{\circ} \mathrm{C}\right]$

10

5

0

$\mathrm{T}$ in $\left[{ }^{\circ} \mathrm{C}\right]$

45

43

41

39

37

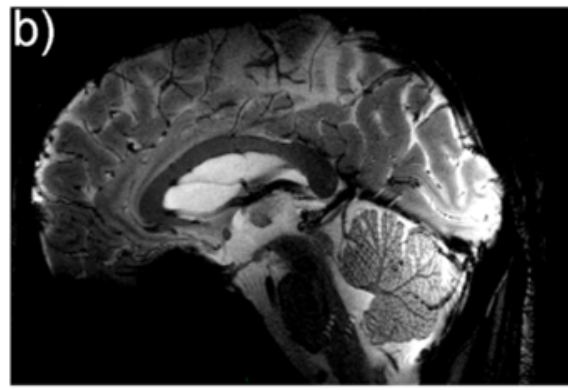

d)

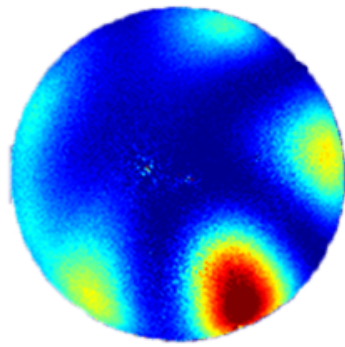

f)

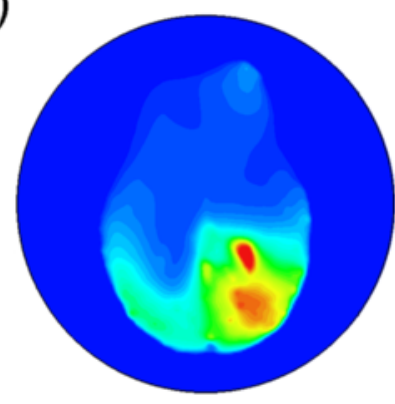

$\Delta \mathrm{T}$ in $\left[{ }^{\circ} \mathrm{C}\right]$

7

4

$\mathrm{T}$ in $\left[{ }^{\circ} \mathrm{C}\right]$

45

43

41

39

37

Fig. 3 a-b MR images of the human brain acquired with the thermal MR 8-channel applicator at 7.0 T. A gradient echo technique is shown with a spatial resolution of $(0.5 \times 0.5 \times 2.0) \mathrm{mm}^{3}$. c MRTh maps of an RF heating experiment on a cylindrical phantom using the applicator to focus SAR in the center of the phantom and to acquire MR images to be used for the MRTh method. The pulsed power RF amplifier of the MR system was used at $300 \mathrm{MHz}\left({ }^{1} \mathrm{H}\right.$ proton excitation frequency at $\left.7.0 \mathrm{~T}\right)$ to induce a temperature difference of $\sim 11^{\circ} \mathrm{C}$ in the center of the phantom after 3 min of RF heating. $\mathbf{d}$ Demonstration of 2D hotspot steering feasibility of the given setup with RF phase modulation between the channels [20]. A temperature of $>7^{\circ} \mathrm{C}$ in the vicinity of the phantom could be reached for an RF heating duration of 2 min. e-f Thermal simulations in human voxel model "Ella" [27] in order to demonstrate the capabilities of the applicator to generate a hotspot in (e) the center of the brain and (f) the periphery applying the same phase setting as in (d) 
and in the vicinity (Fig. 3f) of the human brain. The use of higher RF frequencies for targeted RF heating was found to decrease the hotspot size (Fig. 4). At $500 \mathrm{MHz}$ (Fig. 4c-f), the dimensions of the SAR hotspot are significantly reduced (Table 2 ) from an iso-SAR $90 \%$ value of $(18 \times 18 \times 41) \mathrm{mm}^{3}$ at $300 \mathrm{MHz}$ to an iso-SAR $90 \%$ value of $(10 \times 10 \times 40) \mathrm{mm}^{3}$ for the same antenna building block size (Fig. 4a-d, Table 2). Iso-SAR $75 \%$ was $(29 \times 29 \times 70) \mathrm{mm}^{3}$ for $300 \mathrm{MHz}$ and $(17 \times 17 \times 73) \mathrm{mm}^{3}$ for the same antenna building block size at $500 \mathrm{MHz}$ (Table 2). Since the RF wavelength is shortened at $500 \mathrm{MHz}$, the dipole antenna and size of the dielectric can be reduced to enable smaller building block elements with a size of $(70 \times 40 \times 20) \mathrm{mm}^{3}$ (Fig. $\left.4 \mathrm{e}-\mathrm{f}\right)$ as compared to the larger elements $($ size $=(150 \times 70 \times 40)$ $\mathrm{mm}^{3}$ ) used at $300 \mathrm{MHz}$ and $500 \mathrm{MHz}$ (Fig. 4a-d). The volume reduction of the building block by a factor of $>7$, in particular along the main axis of the bow tie antenna aligned with the $\mathrm{z}$-direction, resulted in a smaller hotspot size (-32\%) along that axis (Table 2). An iso-SAR $90 \%$ of $(10 \times 10 \times 28) \mathrm{mm}^{3}$ and an iso-SAR $75 \%$ of $(17 \times$ $17 \times 48) \mathrm{mm}^{3}$ were found for the 8 -channel setup (Fig. 4e-f, Table 2). The constructed bow tie building blocks are shown in Fig. 2 including a $300 \mathrm{MHz}$ antenna (Fig. 2a, d), the $500 \mathrm{MHz}$ counterpart (Fig. 2b, e) and the smaller $500 \mathrm{MHz}$ version (Fig. 2c, f). The smaller RF antenna building block has the handicap of increased surface SAR values and a reduced absolute SAR value of $116 \mathrm{~W} / \mathrm{kg}$ at the center of the phantom as compared to $176 \mathrm{~W} / \mathrm{kg}$ at $500 \mathrm{MHz}$ and $216 \mathrm{~W} / \mathrm{kg}$ at $300 \mathrm{MHz}$ for an input power of $P_{\text {in }}=400 \mathrm{~W}$ (Table 2). However its smaller size allows for more elements to be placed around the object which holds the promise to potentially reduce surface SAR hotspots, to increase the degree of freedom for transmission field shimming and hotspot steering and to boost the number of receive elements for higher signal-to-noise ratio (SNR) and accelerated acquisitions in an MRI application [32]. a)

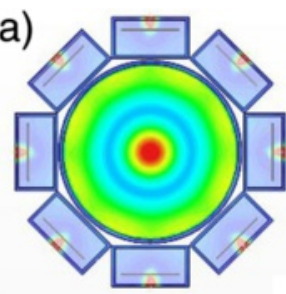

b)

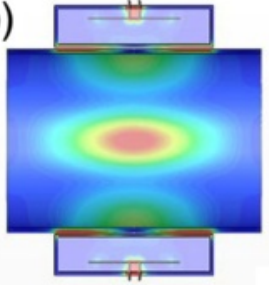

c)

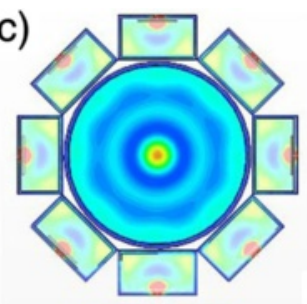

d)

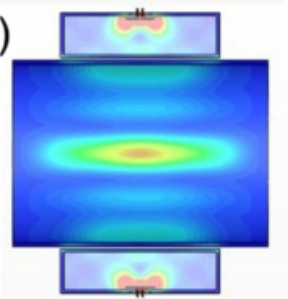

e)

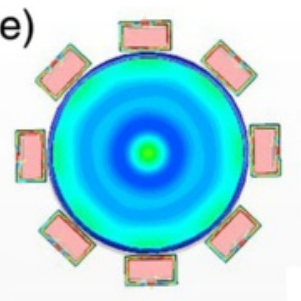

f)
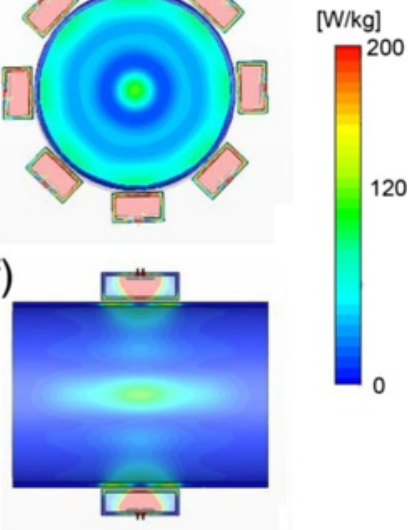

g)

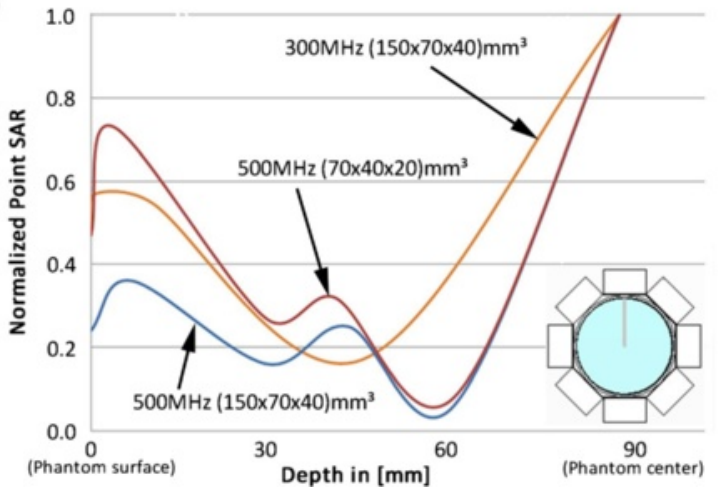

Fig. 4 Comparison of the simulated SAR distributions for three 8-channel bow tie dipole antenna configurations and a total input power of $400 \mathrm{~W}$ ( $50 \mathrm{~W}$ per antenna). (a-b) Bow tie building block at $300 \mathrm{MHz}$ with dimensions $(150 \times 70 \times 40) \mathrm{mm}^{3}$, (c-d) bow tie building block at $500 \mathrm{MHz}$ with dimensions $(150 \times 70 \times 40) \mathrm{mm}^{3}$ and $(\mathbf{e}-\mathbf{f})$ a smaller sized $(70 \times 40 \times 20) \mathrm{mm}^{3}$ bow tie building block at $500 \mathrm{MHz}$. The local SAR hotspot size in the center of the phantom was significantly reduced at $500 \mathrm{MHz}$. A reduction in the length of the dielectric at $500 \mathrm{MHz}$ (e-f) yielded smaller hotspot dimensions along the main axis of the bow tie antenna. (g) Comparison of the normalized point SAR derived from electromagnetic field simulations along a line from the surface to the center of a cylindrical phantom for three 8-channel arrangements of the building blocks. For all configurations the antenna building blocks are driven in phase $\left(\mathrm{Ch} 1-8=0^{\circ}\right)$ to generate a hotspot in the center of the phantom 
Table 2 RF heating performance of 8-channel applicator designs at $300 \mathrm{MHz}$ and $500 \mathrm{MHz}$

\begin{tabular}{lllllll}
\hline Frequency $[\mathrm{MHz}]$ & Dimensions $\left[\mathrm{mm}^{3}\right]$ & Central SAR $[\mathrm{W} / \mathrm{kg}]$ & iso-SAR $90 \%\left[\mathrm{~mm}^{3}\right]$ & iso-SAR $75 \%\left[\mathrm{~mm}^{3}\right]$ & iso-SAR $50 \%\left[\mathrm{~mm}^{3}\right]$ & iso-SAR $25 \%\left[\mathrm{~mm}^{3}\right]$ \\
\hline 300 & $150 \times 70 \times 40$ & 216 & $18 \times 18 \times 41$ & $29 \times 29 \times 70$ & $45 \times 45 \times 111$ & $65 \times 65 \times 157$ \\
500 & $150 \times 70 \times 40$ & 176 & $10 \times 10 \times 40$ & $17 \times 17 \times 73$ & $27 \times 27 \times 138$ & $35 \times 35 \times 182$ \\
500 & $70 \times 40 \times 20$ & 116 & $10 \times 10 \times 28$ & $17 \times 17 \times 48$ & $26 \times 26 \times 83$ & $25 \times 25 \times 155$ \\
\hline
\end{tabular}

Maximum absolute central point SAR for a total input power of $400 \mathrm{~W}$ and hotspot size described by iso-SAR $90 \%$, iso-SAR $75 \%$, iso-SAR $50 \%$ and iso-SAR $25 \%$ along the $\mathrm{x}, \mathrm{y}$ and $\mathrm{z}$ axis for transmit frequencies of $300 \mathrm{MHz}$ and $500 \mathrm{MHz}$ and for antenna building block with different dimensions

\section{Hybrid RF heating at $500 \mathrm{MHz}$}

The results of the RF heating experiments at $500 \mathrm{MHz}$ and MRI at $300 \mathrm{MHz}$ are summarized in Fig. 5 together with the thermal simulations derived from a virtual setup. The external RFPA is not MR compatible and was positioned in the operator room, which made the use of long RF cables necessary to connect the RFPA with the $\mathrm{RF}$ antenna. This connection introduced cables losses of $-2.7 \mathrm{~dB}$ at $500 \mathrm{MHz}$, resulting in a required power output of $130 \mathrm{~W}$ at the RFPA to reach an input power of $70 \mathrm{~W}$ at the antenna. Additional RF losses, which increase with RF frequency, resulted from the deionized water used as a dielectric with a measured electrical conductivity at $500 \mathrm{MHz}$ of $0.14 \mathrm{~S} / \mathrm{m}$. However the RF power achieved was sufficient to generate a maximum temperature increase of $\Delta \mathrm{T}>15{ }^{\circ} \mathrm{C}$ after $12 \mathrm{~min}$ heating in simulations and measurements (Fig. 5). MRTh was performed without any imaging artefacts caused by the RF antenna building block. The measured temperature profile shows good correlation with the simulated data (Fig. 5). Benchmarking of thermal simulations against measurements yielded a temperature difference $<2{ }^{\circ} \mathrm{C}$ for surface regions, which might be attributed to imperfect thermal modelling in these locations. In comparison, a temperature difference of less than $1^{\circ} \mathrm{C}$ was found at depth (>40 mm) (Fig. 5).

\section{Thermal simulations in human voxel models}

The thermal simulation results obtained for an 8channel applicator at $300 \mathrm{MHz}$, an 8-channel applicator at $500 \mathrm{MHz}$ and a 20-channel applicator at $1 \mathrm{GHz}$ positioned around the head of the human voxel model "Ella" are presented in Fig. 6. The hotspot was focused to the center of the brain to demonstrate, that targeted RF heating is not restricted to surface regions and can be performed for deep seated intracranial lesions. For an input power of $400 \mathrm{~W}$ and an RF heating duration of only $3 \mathrm{~min}$, all setups were found capable to deliver sufficient energy absorption in the center of the brain $\left(\operatorname{maxSAR}_{1 \mathrm{~g}}=311 \mathrm{~W} / \mathrm{kg}\right.$ for $300 \mathrm{MHz}$, max$\mathrm{SAR}_{1 \mathrm{~g}}=240 \mathrm{~W} / \mathrm{kg}$ for $500 \mathrm{MHz}$ and $\operatorname{maxSAR}_{1 \mathrm{~g}}=307 \mathrm{~W} /$ $\mathrm{kg}$ for $1 \mathrm{GHz}$ ) in order to reach temperatures above $44{ }^{\circ} \mathrm{C}$. The thermal simulations showed that after $3 \mathrm{~min}$ the $300 \mathrm{MHz}$ setup reached a maximum temperature of $T_{\max }=46.8{ }^{\circ} \mathrm{C}$ in the center of the human brain resulting in a temperature difference of $\Delta T=9.8{ }^{\circ} \mathrm{C}$ versus baseline. This value correlates well with the temperature difference of $\Delta T=10.7{ }^{\circ} \mathrm{C}$ measured previously in phantom experiments using the same RF heating paradigm [20]. At higher RF frequencies the maximum temperature reached was slightly lower with $T_{\max }=44.5^{\circ} \mathrm{C}$ for $500 \mathrm{MHz}$ and $T_{\max }=45.3^{\circ} \mathrm{C}$ at $1 \mathrm{GHz}$. The difference versus the $300 \mathrm{MHz}$ setup can be attributed to pronounced power losses in tissue at these frequencies leading to damping of the electromagnetic waves. While the maximum temperatures in the center of the brain are well above $44{ }^{\circ} \mathrm{C}$ for all configurations, surface regions showed temperature elevations below $43{ }^{\circ} \mathrm{C}$ $\left(41{ }^{\circ} \mathrm{C}\right.$ for $300 \mathrm{MHz}, 39.3{ }^{\circ} \mathrm{C}$ for $500 \mathrm{MHz}$ and $42.9^{\circ} \mathrm{C}$ for $1 \mathrm{GHz}$ ) demonstrating a good selectivity of the approach. Time dependent changes in thermoregulation have not been modeled and might influence absolute achievable temperatures.
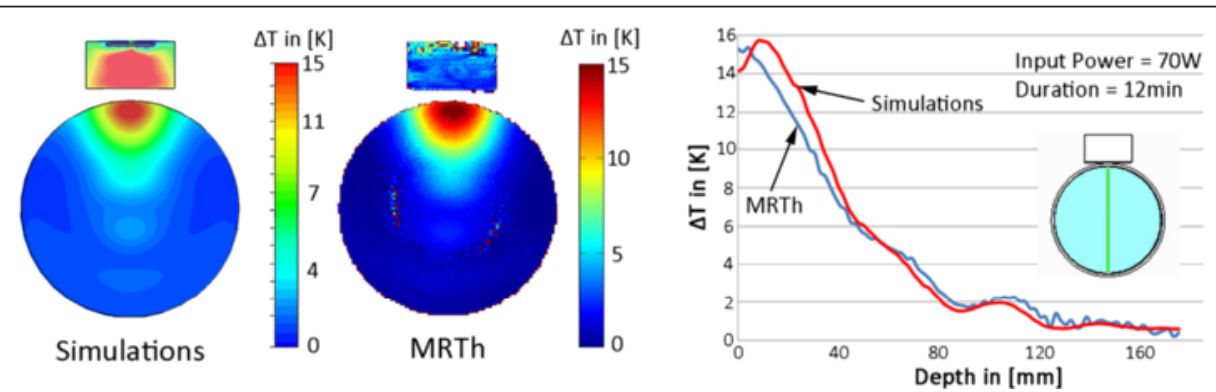

Fig. 5 Comparison of the simulated temperature distribution (left) of a single bow tie antenna driven at $500 \mathrm{MHz}$ in an axial slice of a cylindrical phantom versus MRTh measurements (middle). For simulations and experiments an RF heating paradigm of $70 \mathrm{~W}$ input power and a duration of 12 minutes was employed. Relative temperature distribution ( $\Delta T$ ( $)$ (right) along a central line (marked in green in the inlay showing the setup). A good agreement was found between temperature simulations (red line) and MRTh (blue line) 


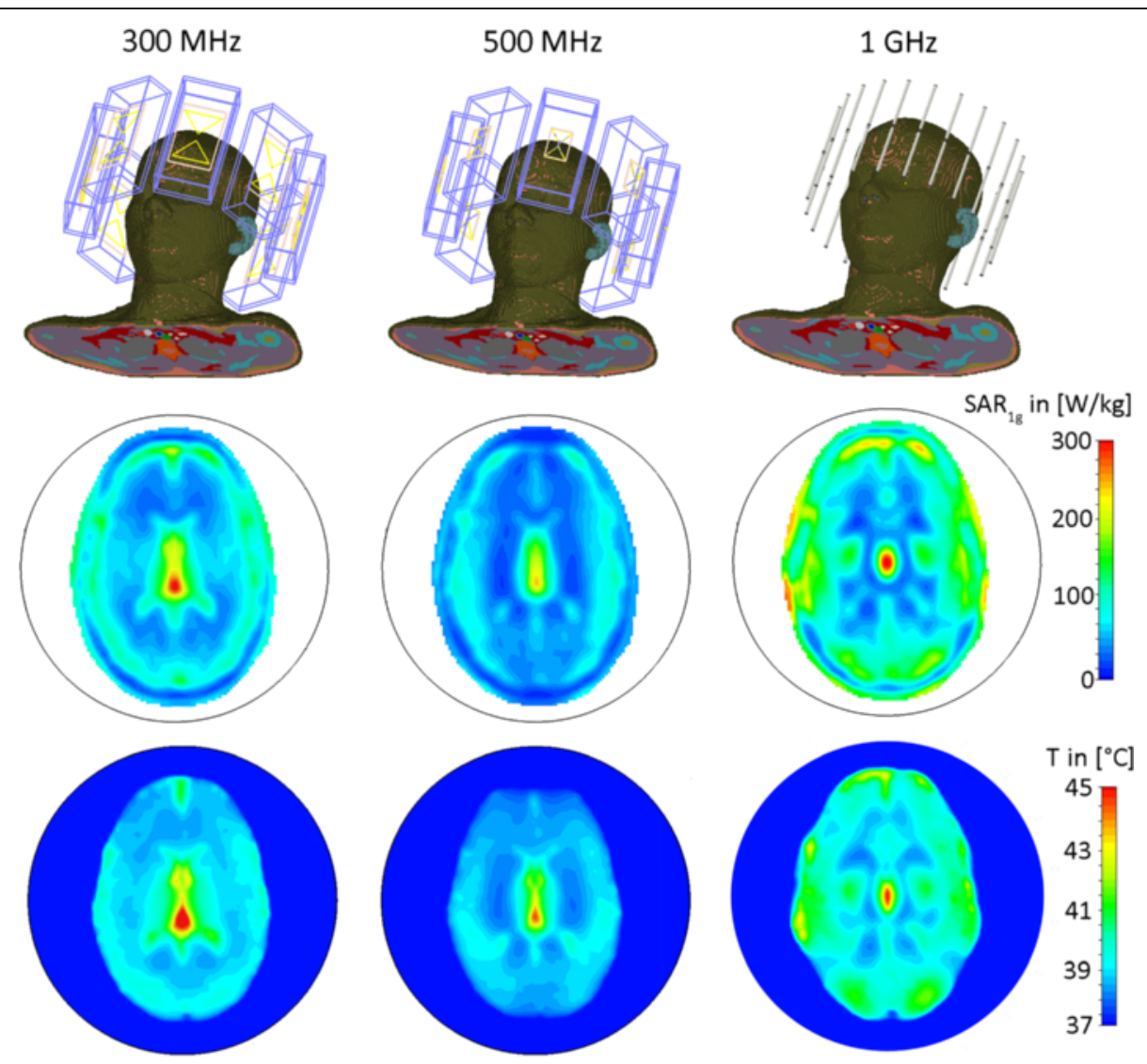

Fig. 6 Comparison of the SAR and thermal distributions from electromagnetic and thermal simulations of three applicator configurations positioned around the head of human voxel model "Ella" [27] with frequency dependent electromagnetic and thermal properties adjusted based on [31]. The configurations include an 8-channel applicator at $300 \mathrm{MHz}$ (left), an 8-channel applicator at $500 \mathrm{MHz}$ (middle) and a 20-channel applicator at $1 \mathrm{GHz}$ (right). All three applicators were driven with a total input power of $P_{\text {in }}=400 \mathrm{~W}$, an in-phase (no phase shift between channels) phase setting, an RF heating duration of $3 \mathrm{~min}$ and a waterbolus temperature of $\mathrm{T}_{\mathrm{B}}=20^{\circ} \mathrm{C}$. Maximum $\mathrm{SAR}_{1 \mathrm{~g}}$ in the center of the brain was $311 \mathrm{~W} / \mathrm{kg}$ for $300 \mathrm{MHz}, 240 \mathrm{~W} / \mathrm{kg}$ for $500 \mathrm{MHz}$ and $307 \mathrm{~W} / \mathrm{kg}$ for $1 \mathrm{GHz}$. The maximum temperatures reached in the center of the brain were found to be $T_{\max }=46.8{ }^{\circ} \mathrm{C}$ at $300 \mathrm{MHz}, T_{\max }=44.5^{\circ} \mathrm{C}$ at $500 \mathrm{MHz}$ and $T_{\max }=45.3^{\circ} \mathrm{C}$ at $1 \mathrm{GHz}$ while surface regions exhibited temperatures below $43{ }^{\circ} \mathrm{C}\left(41{ }^{\circ} \mathrm{C}\right.$ for $300 \mathrm{MHz}, 39.3{ }^{\circ} \mathrm{C}$ for $500 \mathrm{MHz}$ and $42.9^{\circ} \mathrm{C}$ for $\left.1 \mathrm{GHz}\right)$

At higher RF frequencies smaller temperature hotspot dimensions were reached, indicating a more localized RF heating performance. At $300 \mathrm{MHz}$ iso-temperature $90 \%$ of $(6 \times 9) \mathrm{mm}^{2}$, iso-temperature $75 \%$ of $(10 \times 16) \mathrm{mm}^{2}$, isotemperature $50 \%$ of $(18 \times 50) \mathrm{mm}^{2}$ and iso-temperature $25 \%$ of $(56 \times 79) \mathrm{mm}^{2}$ hotspot size was observed for the axial plane (Fig. 6). For $500 \mathrm{MHz}$ the hotspot dimensions were reduced to iso-temperature $90 \%$ of $(5 \times 10) \mathrm{mm}^{2}$, iso-temperature $75 \%$ of $(9 \times 22) \mathrm{mm}^{2}$, iso-temperature $50 \%$ of $(14 \times 44) \mathrm{mm}^{2}$ and iso-temperature $25 \%$ of $(29 \times 64) \mathrm{mm}^{2}$ while at $1 \mathrm{GHz}$ the hotspot size was only iso-temperature $90 \%$ of $(2 \times 8) \mathrm{mm}^{2}$, iso-temperature $75 \%$ of $(5 \times 14) \mathrm{mm}^{2}$, iso-temperature $50 \%$ of $(11 \times 22) \mathrm{mm}^{2}$ and iso-temperature $25 \%$ of $(20 \times 34) \mathrm{mm}^{2}$ (Fig. 6).

All three antenna configurations can potentially be used for thermal MR using 7.0 T, 11.7 $\mathrm{T}$ or $23.5 \mathrm{~T}$ proton MR frequency for targeted RF heating, MRI and MRTh. The necessary average power of $400 \mathrm{~W}$ as being used in the simulation setup can be reached using the standard RFPA of the MR system as previously demonstrated in $300 \mathrm{MHz}$ RF heating experiments [20]. A hybrid approach that makes good use of external RFPAs driven at a higher RF frequency $(f \geq 300 \mathrm{MHz})$ for $\mathrm{RF}$ heating together with a MR system operating at $B_{0}=$ $1.5 \mathrm{~T}(64 \mathrm{MHz})$ or $B_{0}=3.0 \mathrm{~T}(128 \mathrm{MHz})$ for MRI and MRTh is also feasible.

\section{Conclusion}

This study outlines the physical and technical underpinnings of a non-invasive RF hyperthermia device utilizing the MR spin excitation frequency for controlled RF heating (thermal MR). EMF simulations and experiments demonstrate the feasibility of an 8-channel applicator for MR imaging, MR thermometry and controlled targeted RF heating at 7.0 T. Our experiments demonstrated that the pulsed multi-channel transmit system of a 7.0 T MR 
scanner supports targeted RF heating and provides enough power $\left(\mathrm{P}_{\mathrm{avg}}>400 \mathrm{~W}\right)$ to induce a temperature increase of $\sim 10{ }^{\circ} \mathrm{C}$ in $3 \mathrm{~min}$ in the center of a head sized phantom. Our EMF simulations and experimental verifications [20, 29] demonstrate that this system is able to provide $>15 \%$ higher power absorption values in the target region for the same input power as compared to current non MR guided clinical RF hyperthermia systems in the head and neck region, which are able to rise tumor temperatures up to $43{ }^{\circ} \mathrm{C}$ with average input power levels of $\sim 300 \mathrm{~W}[33,34]$. Modification of the RF phases applied allowed for hotspot steering to a deliberately selected location.

Our physics considerations, EMF simulations and preliminary experimental results show that higher RF frequencies allow for a more localized targeted RF heating approach, confirming previous studies $[17,19,20]$. Here the temperature hotspot dimensions could be further reduced at $500 \mathrm{MHz}$ and $1 \mathrm{GHz}$ versus the $300 \mathrm{MHz}$ configuration. Three applicator designs were presented, which can potentially be utilized for thermal MR at $300 \mathrm{MHz}, 500 \mathrm{MHz}$ and $1 \mathrm{GHz}$. All configurations are MR compatible and can be also integrated in a hybrid approach equipped with an external RFPA used for RF heating while MRI is being conducted at lower fields $\left(B_{O}=1.5 \mathrm{~T}, 3.0 \mathrm{~T}\right)$. In particular, our studies demonstrated the feasibility of using an external RFPA for transmission at $500 \mathrm{MHz}$ in conjunction with MRI and MRTh performed at $300 \mathrm{MHz}\left(B_{O}=7.0 \mathrm{~T}\right)$.

In comparison to a hybrid approach, thermal MR has the benefit of making additional RF hardware (RFPA, RF electronics, filters, antennas) or software to drive these components obsolete while adding another therapeutic dimension to a diagnostic MRI device. The use of many element local transmit/receive antennas at ultrahigh fields offers potential signal-to-noise ratio enhancements [35-38]. These enhancements can be translated into spatiotemporal resolution improvements [39, 40] which are beneficial for MR temperature mapping during RF heating interventions. While being important to dynamically control the desired temperature distribution by adjusting the RF pulses played out at the antennas, reliable temperature information is crucial for a thermal dose characterization in locations of intracranial lesion as well as in remote healthy tissue. Although E-field or SAR distributions cannot be measured directly with MR, local SAR can be estimated using MR prior to an $\mathrm{RF}$ heating procedure [41]. This allows for a control and adjustment of the treatment planning parameters of the applicator prior to the treatment. During an RF hyperthermia treatment, MRTh can function as a tool to retrospectively estimate SAR and correct the temperature distribution via amplitude and phase modulation of the RF pulses $[42,43]$. Here the selectivity of the method to provide an accurate thermal dose to a target region is yet to be determined in-vivo. Dynamically played out RF pulses can be optimized based upon the geometry and shape of intracranial lesions using adapted algorithms proposed to manage local SAR hotspots in parallel transmit MR applications [44-46]. The lessons learned from RF induced heating of conductive implants at 7.0 $\mathrm{T}[29,47]$ can be also put to good use to advance targeted RF heating at $300 \mathrm{MHz}$.

Our findings suggest that at $1 \mathrm{GHz}$ sufficient energy can be deposited in the center of the human brain. This result can be exploited for targeted RF heating, but also renders human in-vivo MRI at $23.5 \mathrm{~T}$ or human in-vivo electron paramagnetic resonance (EPR) at $1 \mathrm{GHz}$ and above feasible from an electrodynamic standpoint. While a single transmission element faces an increased power absorption in surface regions at higher RF frequencies, the reduction of the transmitted wavelength enables a higher density placement of the antennas without deteriorating element decoupling. Exploiting this physical advantage, our simulations showed that the number of dipole antennas can be extended to 20 with decoupling values $<-13 \mathrm{~dB}$. At the same time a substrate, which might introduce losses becomes redundant at such high frequencies. The presented 20-channel electric dipole array at $1 \mathrm{GHz}(23.5 \mathrm{~T})$ generates absolute $B_{1}^{+}$values of $\sim 11 \mu \mathrm{T} / \sqrt{ } \mathrm{kW}$ in the center of the human brain while local SAR ( $1 \mathrm{~g}$ average) values are reduced at $1 \mathrm{GHz}$ by a factor of $\sim 2$ as compared to $300 \mathrm{Mhz}$ since the RF power is spread more evenly around the surface of the head [48]. These results provide encouragement for whole-body $\mathrm{MR}$ systems with $B_{0} \geq 7.0 \mathrm{~T}$ which is in alignment with potential future developments of UHF MRI. A recent report of the National Research Council on high magnetic field science and its application forwarded a call for a $20.0 \mathrm{~T}$ wide bore MR system [49]. This development is inspired by the progress at 7.0 T,by the early experience with small animal $\mathrm{MR}$ at $21.1 \mathrm{~T}$ and the advances in ultrahigh field magnet technology $[50,51]$. The requirements of thermal MR are likely to pave the way for further advances in MR technology and MR systems design. With appropriate multi transmit systems that offer more than 8 transmission channels, an optimistically-inclined scientist might envisage the implementation of high density transceiver arrays to break ground for a many element, two-dimensional applicator allowing improvements in imaging performance [36] and hotspot focusing along z-dimension [24-26].

To summarize, the strong rationale for the use of noninvasive hyperthermia as part of a multimodal treatment for patients with glioblastoma asks for innovations $[6,9]$. Non-invasive RF hyperthermia approaches, that combine ultrahigh-field MRI together with controlled and localized RF heating, potentially offer another dimension to 
treatment efficiency and control [20]. Such system, employed for local RF hyperthermia as an alternative additive treatment for glioblastoma multiforme might be able to improve local control [5] by "fighting fire with fire" [9]. Interventions are not limited to an adjuvant to radiotherapy alone, temperature driven targeted drug and contrast agent delivery in conjunction with diagnostic MR imaging and spectroscopy might improve chemotherapeutic approaches with increased drug concentrations at tumor site and reduced drug side effects [52-56]. Applications may not be limited to the brain but could be extended to other body regions and disease models and might help to understand temperature dependent bioand physiological effects in-vivo. A limitation of thermal $M R$ at UHF $(B 0 \geq 7.0 \mathrm{~T})$ are the current costs of the MR system, which might limit RF hyperthermia of the brain to established high-volume treatment centers.

To conclude, the opportunities and capabilities of thermal magnetic resonance for RF hyperthermia interventions are intriguing and in a creative state of flux. Bringing these interventions and therapies into the clinic remains a challenge. A story worth following since the implications feed into a broad spectrum of MR physics, biomedical engineering, oncology, surgery, radiology and other related fields of basic research and clinical science.

\footnotetext{
Abbreviations

$\Lambda$ : Radio frequency wavelength; $B_{0}$ : Static magnetic field used for magnetic resonance imaging; $B_{1}^{+}$: Magnetic resonance spin excitation field; CT: Computed tomography; EMF: Electromagnetic fields; MRI: Magnetic resonance imaging; MRTh: MR thermometry; PRFS: Proton resonance frequency shift; RF: Radio frequency; RFPA: RF power amplifier; SAR: Specific absorption rate; SNR: Signal-to-noise ratio.
}

\section{Competing interests}

Thoralf Niendorf is founder and CEO of MRI.TOOLS GmbH, Berlin, Germany.

\section{Authors' contributions}

LW conceived the study, designed the study, performed electromagnetic field and thermal simulations, performed RF hardware design and RF heating experiments, evaluated the data and drafted the manuscript. CÖ participated in the design of the study, in the RF hardware design and in the RF heating experiments. WH participated in RF hardware design and RF heating experiments. TvdL \& JP performed electromagnetic field simulations, performed RF hardware design and RF heating experiments, and evaluated the data. YJ performed electromagnetic field simulations and revised the manuscript. PW was involved in the design of the study and the revision of the manuscript. PG and VB were involved in the revision of the manuscript. TN conceived the study, evaluated the data and helped to draft the manuscript. All authors read and approved the final manuscript.

\section{Acknowledgements}

The authors wish to acknowledge PD Dr. Bernd Ittermann (Physikalische Technische Bundesanstalt, Berlin, Germany) for technical and other valuable assistance.

\section{Author details}

${ }^{1}$ Berlin Ultrahigh Field Facility (B.U.F.F.), Max-Delbrück Center for Molecular Medicine, Berlin, Germany. ${ }^{2}$ Physikalisch Technische Bundesanstalt (PTB), Berlin, Germany. ${ }^{3}$ Department of Radiation Oncology, Charité Universitätsmedizin Berlin, Berlin, Germany. ${ }^{4}$ Experimental and Clinical Research Center (ECRC), a joint cooperation between the Charité Medical
Faculty and the Max-Delbrück Center for Molecular Medicine, Berlin, Germany. ${ }^{5} \mathrm{MRI}$.TOOLS GmbH, Berlin, Germany.

Received: 12 March 2015 Accepted: 11 September 2015

Published online: 22 September 2015

References

1. Stupp R, Hegi ME, Gilbert MR, Chakravarti A. Chemoradiotherapy in malignant glioma: standard of care and future directions. J Clin Oncol. 2007;25(26):4127-36.

2. Walker MD, Alexander Jr E, Hunt WE, MacCarty CS, Mahaley Jr MS, Mealey Jr J, et al. Evaluation of BCNU and/or radiotherapy in the treatment of anaplastic gliomas: a cooperative clinical trial. J Neurosurg. 1978;49(3):333-43.

3. Stupp R, Hegi ME, Mason WP, van den Bent MJ, Taphoorn MJ, Janzer RC, et al. Effects of radiotherapy with concomitant and adjuvant temozolomide versus radiotherapy alone on survival in glioblastoma in a randomised phase III study: 5-year analysis of the EORTC-NCIC trial. Lancet Oncol. 2009;10(5):459-66.

4. Gebhardt BJ, Dobelbower MC, Ennis WH, Bag AK, Markert JM, Fiveash JB. Patterns of failure for glioblastoma multiforme following limited-margin radiation and concurrent temozolomide. Radiat Oncol. 2014;9(1):130.

5. Souhami L, Seiferheld W, Brachman D, Podgorsak EB, Werner-Wasik M, Lustig $\mathrm{R}$, et al. Randomized comparison of stereotactic radiosurgery followed by conventional radiotherapy with carmustine to conventional radiotherapy with carmustine for patients with glioblastoma multiforme: report of Radiation Therapy Oncology Group 93-05 protocol. Int J Radiat Oncol Biol Phys. 2004;60(3):853-60.

6. Sneed PK, Stauffer PR, McDermott MW, Diederich CJ, Lamborn KR, Prados $M D$, et al. Survival benefit of hyperthermia in a prospective randomized trial of brachytherapy boost+/-hyperthermia for glioblastoma multiforme. Int J Radiat Oncol Biol Phys. 1998;40(2):287-95.

7. Jordan A, Scholz R, Wust P, Fähling H, Felix R. Magnetic fluid hyperthermia (MFH): Cancer treatment with AC magnetic field induced excitation of biocompatible superparamagnetic nanoparticles. J Magn Magn Mater. 1999;201(1):413-9.

8. Maier-Hauff K, Ulrich F, Nestler D, Niehoff H, Wust P, Thiesen B, et al. Efficacy and safety of intratumoral thermotherapy using magnetic iron-oxide nanoparticles combined with external beam radiotherapy on patients with recurrent glioblastoma multiforme. J Neuro Oncol. 2011;103(2):317-24.

9. Titsworth WL, Murad GJ, Hoh BL, Rahman M. Fighting fire with fire: the revival of thermotherapy for gliomas. Anticancer Res. 2014;34(2):565-74.

10. Sapareto S, Dewey W. Thermal dose determination in cancer therapy. Int J Radiat Oncol Biol Phys. 1984;10(6):787.

11. Lewin JS, Nour SG, Connell CF, Sulman A, Duerk JL, Resnick Ml, et al. Phase II clinical trial of interactive MR imaging-guided interstitial radiofrequency thermal ablation of primary kidney tumors: initial experience. Radiology. 2004;232(3):835-45.

12. Holbrook AB, Santos JM, Kaye E, Rieke V, Pauly KB. Real-time MR thermometry for monitoring HIFU ablations of the liver. Magn Reson Med. 2010;63(2):365-73.

13. Wust P, Hildebrandt B, Sreenivasa G, Rau B, Gellermann J, Riess H, et al. Hyperthermia in combined treatment of cancer. Lancet Oncol. 2002;3(8):487-97.

14. Gellermann J, Hildebrandt B, Issels R, Ganter H, Wlodarczyk W, Budach V, et al. Noninvasive magnetic resonance thermography of soft tissue sarcomas during regional hyperthermia. Cancer. 2006;107(6):1373-82.

15. Lüdemann L, Wlodarczyk W, Nadobny J, Weihrauch M, Gellermann J, Wust $P$. Non-invasive magnetic resonance thermography during regional hyperthermia. Int J Hyperthermia. 2010;26(3):273-82.

16. Hildebrandt B, Gellermann J, Riess H, Wust P. Induced hyperthermia in the reatment of cancer. Cancer Management in Man: Chemotherapy, Biological Therapy, Hyperthermia and supporting Measures. San Diego, USA: Springer; 2011. p. 365-77.

17. Paulides MM, Vossen SH, Zwamborn AP, van Rhoon GC. Theoretical investigation into the feasibility to deposit RF energy centrally in the head-and-neck region. Int J Radiat Oncol Biol Phys. 2005;63(2):634-42.

18. Paulides M, Bakker J, Neufeld E, Zee J, Jansen P, Levendag P, et al. The HYPERcollar: A novel applicator for hyperthermia in the head and neck*. Int J Hyperthermia. 2007;23(7):567-76.

19. Dobšícek Trefná H, Vrba J, Persson M. Evaluation of a patch antenna applicator for time reversal hyperthemia. Int J Hyperthermia. 2010;26(2):185-97. 
20. Winter L, Özerdem C, Hoffmann W, Santoro D, Müller A, Waiczies H, et al. Design and Evaluation of a Hybrid Radiofrequency Applicator for Magnetic Resonance Imaging and RF Induced Hyperthermia: Electromagnetic Field Simulations up to 14.0 Tesla and Proof-of-Concept at 7.0 Tesla. Plos ONE. 2013;8(4):e61661

21. Gellermann J, Wlodarczyk W, Feussner A, Fähling H, Nadobny J, Hildebrandt $B$, et al. Methods and potentials of magnetic resonance imaging for monitoring radiofrequency hyperthermia in a hybrid system. Int J Hyperthermia. 2005;21(6):497-513.

22. Paulides M, Bakker J, Hofstetter L, Numan W, Pellicer R, Fiveland E, et al. Laboratory prototype for experimental validation of MR-guided radiofrequency head and neck hyperthermia. Phys Med Biol. 2014;59(9):2139.

23. ICNIRP. ICNIRP guidelines - for limiting exposure to time-varying electric, magnetic and electromagnetic fields (up to $300 \mathrm{GHz}$ ). Health Phys. 1998;74(4):494-522.

24. Crezee J, Van Haaren P, Westendorp H, De Greef M, Kok H, Wiersma J, et al. Improving locoregional hyperthermia delivery using the 3-D controlled AMC-8 phased array hyperthermia system: A preclinical study. Int J Hyperthermia. 2009;25(7):581-92.

25. De Greef M, Kok H, Correia D, Borsboom P, Bel A, Crezee J. Uncertainty in hyperthermia treatment planning: the need for robust system design. Phys Med Biol. 2011;56(11):3233.

26. Togni P, Rijnen Z, Numan W, Verhaart R, Bakker J, van Rhoon G, et al. Electromagnetic redesign of the HYPERcollar applicator: toward improved deep local head-and-neck hyperthermia. Phys Med Biol. 2013;58(17):5997.

27. Christ A, Kainz W, Hahn E, Honegger K, Zefferer M, Neufeld E, et al. The Virtual Family_development of surface-based anatomical models of two adults and two children for dosimetric simulations. Phys Med Biol. 2010;55:N23-38.

28. Wonneberger U, Schnackenburg B, Wlodarczyk W, Walter T, Streitparth F, Rump J, et al. Intradiscal temperature monitoring using double gradient-echo pulse sequences at 1.0 T. J Magn Reson Imaging. 2010;31(6):1499-503.

29. Winter L, Oberacker E, Özerdem C, Ji Y, von Knobelsdorff-Brenkenhoff F, Weidemann $\mathrm{G}$ et al. On the RF heating of coronary stents at 7.0 Tesla MRI. Magn Reson Med. 2014. doi:10.1002/mrm.25483.

30. Kuroda K. Non-invasive MR, thermography using the water proton chemical shift. Int J Hyperthermia. 2005;21(6):547-60.

31. Hasgall P, Neufeld E, Gosselin MC, Klingenböck A, Kuster N. IT'IS Database for thermal and electromagnetic parameters of biological tissues. http:// www.itis.ethz.ch/database. Version 2.4, Published July 30th, 2013. Accessed January 1, 2014. Accessed Version 2.4, July 30th.

32. Roemer P, Edelstein W, Hayes C, Souza S, Mueller O. The NMR phased array. Magn Reson Med. 1990;16(2):192-225

33. Paulides MM, Bakker JF, van Rhoon GC. Electromagnetic head-and-neck hyperthermia applicator: experimental phantom verification and FDTD model. Int J Radiat Oncol Biol Phys. 2007;68(2):612-20.

34. Paulides M, Bakker J, Linthorst M, Van der Zee J, Rijnen Z, Neufeld E, et al. The clinical feasibility of deep hyperthermia treatment in the head and neck: new challenges for positioning and temperature measurement. Phys Med Biol. 2010:55(9):2465.

35. Niendorf T, Sodickson DK, Krombach GA, Schulz-Menger J. Toward cardiovascular MRI at $7 \mathrm{~T}$ : clinical needs, technical solutions and research promises. Eur Radiol. 2010;20:2806-16.

36. Winter L, Kellman P, Renz W, Gräßl A, Hezel F, Thalhammer C, et al. Comparison of three multichannel transmit/receive radiofrequency coil configurations for anatomic and functional cardiac MRI at 7.0 T: implications for clinical imaging. Eur Radiol. 2012;22(10):2211-20. doi:10.1007/s00330-012-2487-1.

37. Niendorf T, Graessl A, Thalhammer C, Dieringer MA, Kraus O, Santoro D, et al Progress and promises of human cardiac magnetic resonance at ultrahigh fields: A physics perspective. J Magn Reson. 2012;229(0):208-22. doi: http:// dx.doi.org/10.1016/j.jmr.2012.11.015.

38. Niendorf T, Paul K, C O, Graessl A, Klix S, Huelnhagen T et al. W(h)ither Human Cardiac and Body Magnetic Resonance at Ultrahigh Fields? Technical Advances, Practical Considerations, Applications, and Clinical Opportunities. NMR Biomed. 2015. doi:10.1002/nbm.3268.

39. Niendorf T, Sodickson DK. Parallel imaging in cardiovascular MRI: methods and applications. NMR Biomed. 2006;19(3):325-41.
40. Niendorf T, Sodickson DK. Highly accelerated cardiovascular MR imaging using many channel technology: concepts and clinical applications. Eur Radiol. 2008;18(1):87-102.

41. Voigt T, Homann H, Katscher U, Doessel O. Patient-individual local SAR determination: In vivo measurements and numerical validation. Magn Reson Med. 2012;68(4):1117-26.

42. Weihrauch M, Wust P, Weiser M, Nadobny J, Eisenhardt S, Budach V, et al. Adaptation of antenna profiles for control of MR guided hyperthermia (HT) in a hybrid MR-HT system. Med Phys. 2007;34(12):4717-25.

43. Ranneberg M, Weiser M, Weihrauch M, Budach V, Gellermann J, Wust P. Regularized antenna profile adaptation in online hyperthermia treatment. Med Phys. 2010;37(10):5382-94.

44. Zhu Y. Parallel excitation with an array of transmit coils. Magn Reson Med. 2004;51(4):775-84.

45. Cloos MA, Luong M, Ferrand G, Amadon A, Le Bihan D, Boulant N. Local SAR reduction in parallel excitation based on channel-dependent Tikhonov parameters. J Magn Reson Imaging. 2010;32(5):1209-16.

46. Pendse M, Rutt B. An Algorithm for Maximum-SAR Targeted RF Hyperthermia. Proc Intl Soc Mag Reson Med. 2015.

47. Santoro D, Winter L, Müller A, Vogt J, Renz W, Özerdem C, et al. Detailing Radio Frequency Heating Induced by Coronary Stents: A 7.0 Tesla Magnetic Resonance Study. PLos ONE. 2012;7(11):e49963.

48. Winter $L$, Niendorf $T$. On the electrodynamic constraints and antenna array design for human in vivo MR up to 70 Tesla and EPR up to $3 \mathrm{GHz}$. Proc Intl Soc Mag Reson Med. 2015.

49. Committee to Assess the Current Status and Future Direction of High Magnetic Field Science in the United States; Board on Physics and Astronomy; Division on Engineering and Physical Sciences; National Research Council. Washington, DC, USA: The National Academies Press. 2013.

50. Fu R, Brey W, Shetty K, Gorkov P, Saha S, Long J, et al. Ultra-wide bore $900 \mathrm{MHz}$ high-resolution NMR at the National High Magnetic Field Laboratory. J Magn Reson. 2005;177(1):1-8.

51. Smeibidl P, Bird M, Ehmler H, Tennant A. New hybrid magnet system for structure research at highest magnetic fields and temperatures in the millikelvin region. J Phys Conf Series. 2012:400.

52. Ponce AM, Viglianti BL, Yu D, Yarmolenko PS, Michelich CR, Woo J, et al. Magnetic resonance imaging of temperature-sensitive liposome release: drug dose painting and antitumor effects. J Natl Cancer Inst. 2007;99(1):53-63.

53. Langereis S, Keupp J, van Velthoven JU, de Roos IHC, Burdinski D, Pikkemaat JA, et al. A temperature-sensitive liposomal 1H CEST and $19 \mathrm{~F}$ contrast agent for MR image-guided drug delivery. J Am Chem Soc. 2009;131(4):1380-1.

54. Issels RD, Lindner LH, Verweij J, Wust P, Reichardt P, Schem BC, et al. Neoadjuvant chemotherapy alone or with regional hyperthermia for localised high-risk soft-tissue sarcoma: A randomised phase 3 multicentre study. Lancet Oncol. 2010;11(6):561-70.

55. Barreto JA, O'Malley W, Kubeil M, Graham B, Stephan H, Spiccia L. Nanomaterials: applications in cancer imaging and therapy. Adv Mater. 2011;23(12):H18-40.

56. Dunn AE, Dunn DJ, Macmillan A, Whan R, Stait-Gardner T, Price WS, et al Spatial and temporal control of drug release through $\mathrm{pH}$ and alternating magnetic field induced breakage of Schiff base bonds. Polym Chem. 2014;5(10):3311-5.

\section{Submit your next manuscript to BioMed Central and take full advantage of:}

- Convenient online submission

- Thorough peer review

- No space constraints or color figure charges

- Immediate publication on acceptance

- Inclusion in PubMed, CAS, Scopus and Google Scholar

- Research which is freely available for redistribution 